\title{
Spontaneous circulation of myeloid-lymphoid-initiating cells and SCID-repopulating cells in sickle cell crisis
}

\author{
Christopher E.D. Lamming, ${ }^{1}$ Lance Augustin, ${ }^{2}$ Mark Blackstad, ${ }^{1}$ Troy C. Lund, ${ }^{1}$ \\ Robert P. Hebbel, ${ }^{3}$ and Catherine M. Verfaillie ${ }^{1,3}$ \\ ${ }^{1}$ Stem Cell Institute, \\ ${ }^{2}$ Division of Gastroenterology, and \\ ${ }^{3}$ Division of Hematology, Oncology and Transplantation, University of Minnesota, Minneapolis, Minnesota, USA
}

\begin{abstract}
The only curative therapy for sickle cell disease (SCD) is allogeneic hematopoietic stem cell (HSC) transplantation. Gene therapy approaches for autologous HSC transplantation are being developed. Although earlier engraftment is seen when cells from GCSF-mobilized blood are transplanted than when bone marrow is transplanted, administration of GCSF to patients with SCD can cause significant morbidity. We tested whether primitive hematopoietic progenitors are spontaneously mobilized in the blood of patients with SCD during acute crisis (AC-SCD patients). The frequency of myeloidlymphoid-initiating cells (ML-ICs) and SCID-repopulating cells (SRCs) was significantly higher in blood from AC-SCD patients than in blood from patients with steady-state SCD or from normal donors. The presence of SRCs in peripheral blood was not associated with detection of long-term culture-initiating cells, consistent with the notion that SRCs are more primitive than long-term culture-initiating cells. As ML-ICs and SRCs were both detected in blood of AC-SCD patients only, these assays may both measure primitive progenitors. The frequency of ML-ICs also correlated with increases in stem cell factor, GCSF, and IL-8 levels in AC-SCD compared with steady-state SCD and normaldonor sera. Because significant numbers of ML-ICs and SRCs are mobilized in the blood without exogenous cytokine treatment during acute crisis of $S C D$, collection of peripheral blood progenitors during crisis may yield a source of autologous HSCs suitable for ex-vivo correction by gene therapy approaches and subsequent transplantation.
\end{abstract}

J. Clin. Invest. 111:811-819 (2003). doi:10.1172/JCI200315956.

\section{Introduction}

Sickle cell disease (SCD) is an inherited hemoglobinopathy that arises from a single-base substitution at codon 6 of the $\beta$-globin gene, resulting in the conversion of valine to glutamic acid. It is one of the most common forms of inherited anemia, affecting 150 million people worldwide, predominantly of African or Afro-Caribbean descent.

Patients with SCD are characterized by chronic hemolytic anemia, erythroid hyperplasia in the bone marrow, and reticulocytosis. SCD has acute, chronic, and recurrent complications. The acute painful episode, or crisis, is the most common complaint of

Received for publication May 17, 2002, and accepted in revised form January 28, 2003.

Address correspondence to: Catherine M. Verfaillie, Stem Cell Institute, University of Minnesota, MMC 716, 420 Delaware Street SE, Minneapolis, Minnesota 55455, USA. Phone: (612) 625-0602; Fax: (612) 624-2436;

E-mail:verfa001@tc.umn.edu.

Conflict of interest: The authors have declared that no conflict of interest exists.

Nonstandard abbreviations used: sickle cell disease (SCD); homozygous mutation for sickle hemoglobin (HbSS); peripheral blood (PB); natural killer initiating cell (NK-IC); alophycocyanin (APC); sickle cell disease in steady state (SS-SCD); normal (NL); sickle cell disease in acute crisis (AC-SCD); hematopoietic stem cell (HSC); stem cell factor (SCF); long-term culture-initiating cell (LTC-IC); myeloid-lymphoid-initiating cell (ML-IC); SCID-repopulating cell (SRC). patients and is often referred to as the hallmark of the disease. Crises are more common during infancy and in the third and fourth decades of life. The mortality rate is considerably increased in those adults with more frequent painful crises.

The median life expectancy of patients with SCD in the USA is 42 years for men and 48 years for women (1). The only curative therapy is hematopoietic cell transplantation. The first allogeneic hematopoietic cell transplantation for SCD was carried out in 1984 (2). More recently, nonmyeloablative conditioning regimes have been used, as dramatic clinical improvements can be observed with low rates of hematopoietic chimerism in SCD patients $(3,4)$. Because of the lack of allogeneic HLA-matched donors and toxicity associated with allogeneic hematopoietic cell transplantation, various approaches to the genetic modification of autologous hematopoietic stem cells (HSCs) are currently being investigated $(5,6)$.

Use of cytokines, particularly GCSF, to mobilize HSCs and progenitors in the blood has revolutionized autologous hematopoietic cell transplantation (7). Other cytokines enhance mobilization of stem and progenitor cells into the peripheral blood (PB), including stem cell factor (SCF), IL-3, and thrombopoietin (8-10). Combinations of these factors, particularly SCF and GCSF, increase the number and quality of progenitors mobilized (11). However, the 
use of cytokines in SCD may have a detrimental effect in patients in acute crisis, as shown by recent reports of fatalities following administration of $\operatorname{GCSF}(12,13)$.

Several studies have noted that increased numbers of $\mathrm{CD} 34^{+}$cells circulate in the PB of SCD patients. The number of erythroid blast-forming units is elevated in the blood of patients with homozygous mutation for sickle hemoglobin (HbSS) and HbS $\beta$-thalassemia (14), suggesting increased erythropoiesis in response to anemia and increased sensitivity of progenitors to erythropoietin. Other studies have shown that CFCs (15) and long-term culture-initiating cells (LTC-ICs) (16) are increased in the blood of SCD patients. The mechanism for this is not clear. Levels of IL-8, a chemokine known to mobilize stem and progenitor cells in animal models (17), are increased in SCD patients in acute chest crisis, possibly as a result of infections (18). Increased levels of GCSF have been found in the bronchoalveolar fluid in SCD patients in acute chest crisis (19). Levels of IL-3 are consistently elevated in severe SCD patients, and high levels of SCF, another cytokine implicated in hematopoietic stem cell (HSC) mobilization (20), have also been shown in SCD patients in acute chest crisis (21). Finally, GM-CSF levels are raised in SCD and can be directly correlated to the increased hematopoiesis seen in moderate to severe SCD (22).

HSCs are able to self-renew and to give rise to all hematopoietic cell lineages. In mouse models, both the phenotype and the function of HSCs have been characterized using competitive in vivo repopulation assays (23). To measure human HSCs, alternative in vivo or in vitro assays are needed, as competitive repopulation assays cannot be performed. Several in vitro assays have been described that assess primitive human progenitors. A stroma-based system, termed myeloid-lymphoid-initiating cell (ML-IC) assay, has been developed in our laboratory that measures primitive progenitors capable of generating both myeloid and lymphoid LTC-ICs (24). In vivo xenotransplantation models, using either immunodeficient mice (25) or preimmune fetal sheep (26), are also used to assess human HSCs. One study showed engraftment of $\mathrm{CD} 34^{+}$cells from bone marrow of patients with SCD and $\beta$-thalassemia in NOD/SCID mice, with subsequent appearance of erythroid, myeloid, and B lymphoid cells in the PB (27).

In this study we determined the presence of ML-ICs and SCID-repopulating cells (SRCs) in PB collected from HbSS patients in acute crisis, HbSS patients not in acute crisis, and normal healthy volunteers, without administration of cytokines. We found that large numbers of ML-ICs as well as SRCs are mobilized in the blood of HbSS patients during crisis, and that this correlates with high levels of GCSF and SCF.

\section{Methods}

Patients and normal donors. Twenty patients with SCD (HbSS) were selected, seven from among those attending the Fairview University Hospital Hematology clinics and 13 from among those admitted acutely to the inpatient Hematology ward (Fairview University Hospital, Minneapolis, Minnesota, USA). Informed consent according to the guidelines of the University of Minnesota Institutional Review Board for the Use of Humans in Research was obtained from patients before trial entry. Fifty milliliters of PB was drawn for estimation of plasma SCF and GCSF levels as well as CD34 cells, ML-ICs, and SRCs. Patient demographic data, etiology of sickle cell crisis, and other patient characteristics are shown in Table 1. PB samples $(50-200 \mathrm{ml} ; n=10)$ were also collected from normal healthy volunteers with informed consent.

Patients with non-Hodgkin $(n=4)$ or Hodgkin lymphoma $(n=4)$ who were undergoing autologous transplantation as part of their treatment were selected from those attending the Fairview University Hospital Hematology clinics. Informed consent according to the guidelines of the University of Minnesota Institutional Review Board for the Use Of Humans In Research was obtained from patients before trial entry. All patients completed mobilization. PBMCs were obtained by apheresis on day 5 and day 6 following mobilization with either $5 \mu \mathrm{g} / \mathrm{kg}$ GCSF (Filgastrim; Amgen Inc., Thousand Oaks, California, USA) for 6 days $(n=4)$ or $5 \mu \mathrm{g} / \mathrm{kg}$ GCSF and $20 \mu \mathrm{g} / \mathrm{kg} \mathrm{SCF}$ (Amgen Inc.) for 6 days $(n=4)$.

LTC-IC, natural killer initiating cell, and ML-IC assay. $\mathrm{CD} 34^{+}$cells and $\mathrm{CD} 34^{+} \mathrm{CD} 38^{-} \mathrm{Lin}^{-}$cells were selected as previously described (24). Single $\mathrm{CD} 34^{+} \mathrm{CD} 38^{-} \mathrm{Lin}^{-}$cells were plated in the ML-IC assay, and LTC-ICs, natural killer initiating cells (NK-ICs), and ML-ICs were enumerated as previously described (24).

Cytokine measurement. All serum samples were frozen at $-70^{\circ} \mathrm{C}$ and thawed once at the time of the assay. All samples were assayed in duplicate. GCSF, SCF, GM-CSF, and IL-8 levels were measured using an ELISA kit (Quantikine Kit; R\&D Systems Inc., Minneapolis, Minnesota, USA). The assay sensitivities were $0.5 \mathrm{pg} / \mathrm{ml}$ for GCSF, $0.8 \mathrm{pg} / \mathrm{ml}$ for SCF, 0.1 $\mathrm{pg} / \mathrm{ml}$ for GM-CSF, and $0.5 \mathrm{pg} / \mathrm{ml}$ for IL-8. One-hundred-microliter samples were dispensed in 96-well microtiter plates of the Quantikine Kit and incubated at room temperature for 2 hours. The plates were then rinsed four times with wash buffer and incubated for 2 hours with anti-cytokine HRP conjugate that corresponded to each of the cytokines tested. The bound enzyme was then detected by incubation with tetramethylbenzidine and hydrogen peroxide as a substrate and then quantified using a microplate reader (Bio-Rad, Melville, New York, USA).

NOD/SCID transplantation. NOD/SCID mice were kept in a pathogen-free mouse facility with sterilized food and bedding in accordance with guidelines from the University of Minnesota's Institutional Animal Committee. Mice aged 6-8 weeks were used for studies of human engraftment. They were sublethally irradiated with $275 \mathrm{cGy}$ (dose rate $50 \mathrm{cGy} / \mathrm{min}$ ) in a 
Table 1

Patient characteristics

\begin{tabular}{|c|c|c|c|c|}
\hline Age & $\begin{array}{c}\text { Crisis etiology or } \\
\text { steady state (SS-SCD) }\end{array}$ & $\begin{array}{c}\text { WBCs } \times 10^{9} \\
\text { per ml PB } \\
\text { on day of } \\
\text { sample collection }\end{array}$ & $\begin{array}{c}\text { Hemoglobin } \\
(\mathrm{g} / \mathrm{dl}) \text { on day of } \\
\text { sample collection }\end{array}$ & $\begin{array}{l}\text { Hemoglobin } \\
(\%)\end{array}$ \\
\hline 31 & Infection & 28.9 & 6.7 & 6.1 \\
\hline 35 & Acute pain & 15.2 & 12.4 & 8.1 \\
\hline 22 & Infection & 12.9 & 7.8 & 7.5 \\
\hline 26 & Sequestration & 31.8 & 6.5 & 9.1 \\
\hline 30 & Chest crisis & 21.6 & 8.8 & 8.8 \\
\hline 32 & Acute painful crisis & 17.7 & 8.9 & 5.1 \\
\hline 33 & Infection & 25.5 & 7.1 & 10.0 \\
\hline 27 & Painful hip? Avascular necrosis & 14.2 & 10.3 & 4.5 \\
\hline 25 & Chest crisis & 19.1 & 6.9 & 6.4 \\
\hline 19 & Infection & 33.6 & 9.2 & 8.9 \\
\hline 28 & Infection & 30.1 & 11.1 & 9.2 \\
\hline 37 & Chest crisis & 38.8 & 10.6 & 7.9 \\
\hline 31 & Infection & 23.1 & 8.9 & 5.5 \\
\hline 19 & Steady state & 6.9 & 9.6 & 8.3 \\
\hline 28 & Steady state & 8.8 & 12.0 & 7.0 \\
\hline 35 & Steady state & 11.1 & 12.5 & 6.5 \\
\hline 27 & Steady state & 5.6 & 10.4 & 4.4 \\
\hline 33 & Steady state & 4.1 & 8.0 & 5.2 \\
\hline 32 & Steady state & 1.7 & 9.1 & 3.5 \\
\hline 26 & Steady state & 2.6 & 7.7 & 5.0 \\
\hline
\end{tabular}

WBC, white blood cells. anti-human CD45-phycoerythrin, anti-mouse CD45-FITC, and anti-human CD14, -human CD19, -human CD33, and -human CD34 APC (Becton Dickinson Immunocytometry Systems, San Jose, California, USA) to detect multilineage engraftment of human cells using appropriate isotype-control antibodies. Bone marrow harvested from both femurs and both tibiae of mice with about $2 \%$ human CD 45 cells was transplanted 1:1 into secondary irradiated NOD/SCID recipients, which were again sacrificed and analyzed 6 weeks after transplantation.

PCR analysis of samples. Using the DNeasy Tissue Kit (QIAGEN Inc., Valencia, California, USA) according to the manufacturer's instructions, we isolated genomic DNA from aliquots of blood, bone marrow, and spleen samples collected from animals transplanted with human SCD CD $34^{+}$cells frozen at $-20^{\circ} \mathrm{C}$ in RNAlater (Ambion Inc.,

cesium irradiator. Twenty-four hours after irradiation, $\mathrm{CD} 34^{+}$cells from SCD patients or normal donors were injected via the tail vein. Mice received all $\mathrm{CD} 34^{+}$cells selected from $50 \mathrm{ml} \mathrm{PB}$ (between $2.0 \times 10^{5}$ and $3.7 \times 10^{5} \mathrm{CD} 34^{+}$cells) with $2.6 \times 10^{6}$ to $2.8 \times 10^{6}$ irradiated normal carrier cells, or $0.5 \times 10^{6}$ to $3.0 \times 10^{6} \mathrm{CD} 34^{-}$cells from SCD patients in acute crisis or steady state. As control, mice were injected with all $\mathrm{CD} 34^{+}$cells selected from $200 \mathrm{ml} \mathrm{PB}$ from normal volunteer donors $\left(2.0 \times 10^{4}\right.$ to $5.0 \times 10^{4}$ CD $34^{+}$cells with $3 \times 10^{6}$ irradiated normal carrier cells). After 6 weeks, mice were sacrificed by cervical dislocation following carbon dioxide asphyxiation. Bone marrow was collected by flushing of both femurs and both tibiae with RPMI (GIBCO BRL; Life Technologies Inc., Grand Island, New York, USA) and $20 \%$ FCS. Erythrocytes were lysed using a hypertonic lysis buffer, and bone marrow cells were incubated for 30 minutes in PBS containing 10\% mouse and $10 \%$ rat serum (Caltag Laboratories Inc., Burlingame, California, USA). Samples were then stained with

\footnotetext{
Figure 1

FACS analysis for $\mathrm{CD} 34^{+} \mathrm{CD} 38^{-} \mathrm{Lin}^{-}$cells in PB of $\mathrm{NL}$ donors and SS-SCD and AC-SCD patients. CD34+ cells were selected as described in Methods, stained with CD34 APC, CD38 FITC, and lineage phycoerythrin (Lin-PE) antibodies, and selected by FACS. Live cells were gated in R1, and then CD34 cells were gated against lineage cells. R2 represents the $C D 34^{+} \mathrm{Lin}^{-}$gate. Cells in $\mathrm{R} 2$ were gated as CD34 versus CD38. The R3 gate, CD34+CD38- (not shown here), was used to sort for single-cell deposition for assays.
}

Austin, Texas, USA). PCR amplification of a 345-bp fragment of the $\beta$-globin gene was accomplished using primers BG02 (TCCTAAGCCAGTGCCAGAAGAG) and BG05 (CTATTGGTCTCCTTAAACCT) (IDT, Coralville, Iowa, USA) and Pfu Turbo Hotstart DNA polymerase (QIAGEN Inc.) in $50 \mu \mathrm{l}$ as follows: $95^{\circ} \mathrm{C}$ for 3 minutes, followed by 35 or 40 cycles of $95^{\circ} \mathrm{C}$ for

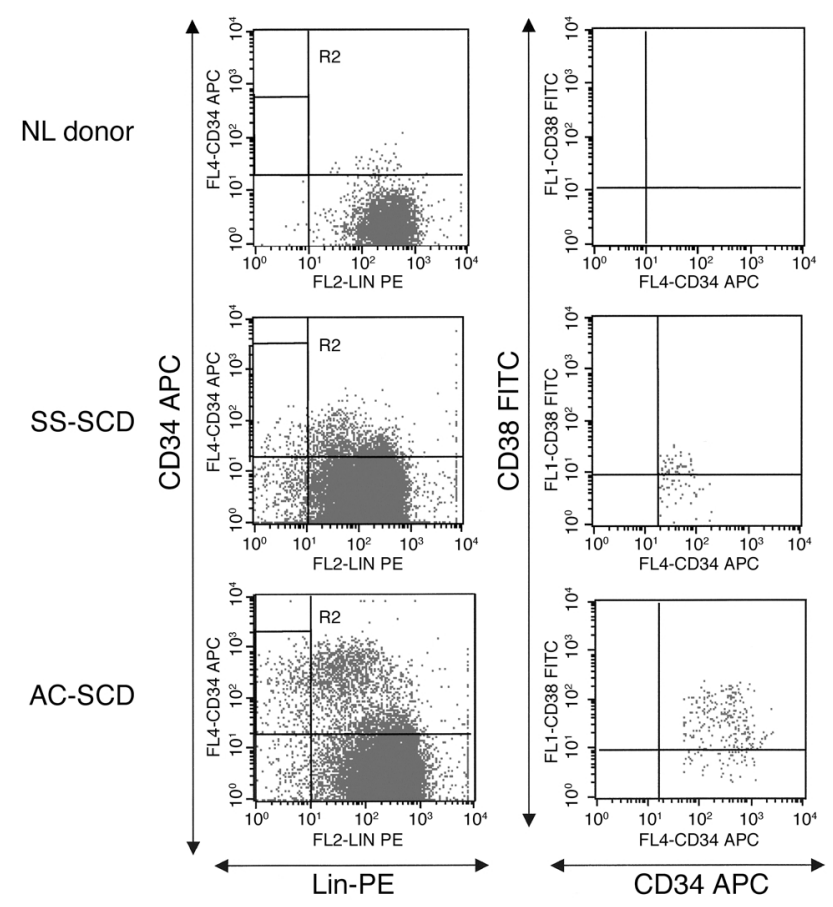




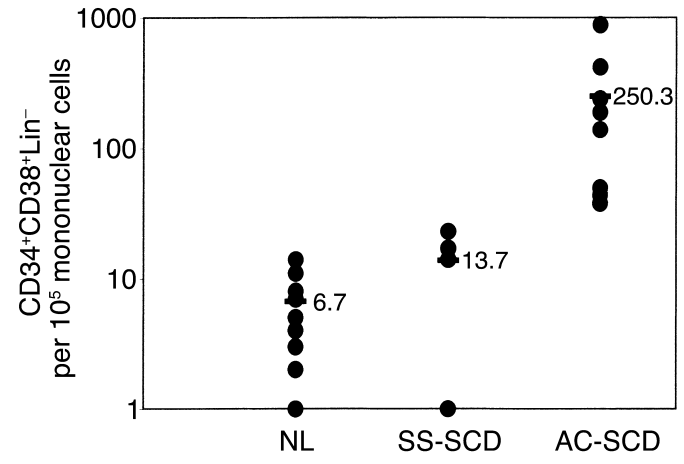

Figure 2

Significantly more $\mathrm{CD} 34^{+} \mathrm{CD} 38^{-}$Lin $^{-}$cells are present per $10^{5} \mathrm{PBMCs}$ from AC-SCD patients compared with NL donors and SS-SCD patients. Mononuclear cells were selected from blood from normal donors, SS-SCD patients, and AC-SCD patients. Following enrichment for $\mathrm{CD}^{2} 4^{+}$cells and $\mathrm{Lin}^{-}$cells, CD34+CD38- Lin $^{-}$cells were selected by FACS. Significantly more CD $34^{+} \mathrm{CD} 38$-Lin ${ }^{-}$cells were detected among mononuclear cells from AC-SCD blood compared with SS-SCD and NL-donor blood. Differences between the groups were evaluated by Student's $t$ test.

30 seconds, $50-60^{\circ} \mathrm{C}$ for 30 seconds, and $72^{\circ} \mathrm{C}$ for 1 minute, followed by $72^{\circ} \mathrm{C}$ for 10 minutes. PCR products were digested with DdeI restriction endonuclease and analyzed by electrophoresis through $2 \%$ agarose gels. Gels were stained with ethidium bromide (Sigma-Aldrich, St. Louis, Missouri, USA) and digitally photographed with a Kodak EDAS 290 gel documentation system (Eastman Kodak Co. Scientific Imaging Systems, Rochester, New York, USA).

Quantitative PCR for buman cell engraftment. Real-time PCR was performed using an ABI PRISM 7700

\section{Figure 3}

Significantly more LTC-ICs (a), NK-ICs (b), and ML-ICs (c) are present in $\mathrm{CD} 34^{+} \mathrm{CD} 38-$ Lin $^{-}$cells from AC-SCD patients than in those from NL donors or SS-SCD patients. Single CD34+CD38- Lin $^{-}$cells, selected by FACS from normal donors (44-66 wells plated), SS-SCD patients (66-88 wells plated), and AC-SCD patients (66-132 wells plated), were plated in ML-IC assays as previously described (24). After 2 weeks, single CD34 ${ }^{+} \mathrm{CD} 38^{-}$Lin $^{-}$cell progeny were replated in four individual wells, two of which were maintained under LTC-IC and two under NK-IC conditions. For LTC-IC cultures, wells were overlaid after 5 weeks with clonogenic medium, and the presence of CFCs was determined 2 weeks later. NK-IC cells were harvested after 5 weeks and evaluated by FACS for the presence of CD56+ NK cells or CD19+ $B$ cells. An LTC-IC was determined as a well in LTC-IC cultures where CFCs were present without NK and/or B cells being present in the companion NK-IC cultures. An NK-IC was determined as a well in NK-IC cultures where NK and/or $B$ cells were present without CFCs being present in the companion LTC-IC cultures. An ML-IC was identified when progeny of the initial CD34+CD38- Lin $^{-}$cell gave rise to at least one LTC-IC and at least one NK-IC. Significantly more LTC-ICs, NK-ICs, and ML-ICs were present among CD34 ${ }^{+} \mathrm{CD} 38^{-}$Lin $^{-}$cells in AC-SCD blood compared with blood from SS-SCD patients and NL donors. Values shown as 0 represent frequencies below the detection level of the assays. As we plated between 44 and 132 wells, this indicates that fewer than one ML-IC was present among 44-132 CD34+CD38-Lin- cells. Differences between the groups were evaluated by $t$ test. sequence detector with the accompanying software (version 1.6; Applied Biosystems, Foster City, California, USA). Reaction conditions for amplification of human microsatellite DNA were as follows: 40 cycles of two-step PCR $\left(95^{\circ} \mathrm{C}\right.$ for 15 seconds, $60^{\circ} \mathrm{C}$ for 60 seconds) after initial denaturation $\left(95^{\circ} \mathrm{C}\right.$ for 10 minutes) with $1 \mu \mathrm{l}$ of DNA as template, $50 \mu \mathrm{M}$ of each primer, and $1 \times$ SYBR-green PCR Master Mix (Applied Biosystems). The PCR primers were designed using Primer Express software (version 1.0; Applied Biosystems) as follows: hSat(f), ATTCACGTCACAAACTGAACATTC; hSat( $\mathrm{r})$, CGTTTGAAATGTCCGTTTGTAGAT. The result was normalized to $18 \mathrm{~S}$ rRNA, forward primer $5^{\prime}$ GTAACCCGTTGAACCCCATT- $3^{\prime}$ and reverse primer $5^{\prime}$ CCATCCAATCGGTAGTAGCG-3' DNA, and calculated in reference to a mixed sample of human K562 and murine AFT024 cells.

Statistics. Where applicable, we assessed correlations between cytokine levels and ML-IC frequency in SCD patients in steady state (SS-SCD patients), SCD patients in crisis, and normal donors, using correlation coefficients. Groups were compared by unpaired $t$ test, $\chi$-squared test, or block ANOVA using the Microsoft Excel statistical package (Microsoft Corp., Seattle, Washington, USA).

\section{Results}

Increased numbers of primitive progenitors are present in the $P B$ during acute crisis of $S C D$. We initially evaluated the number of $\mathrm{CD} 34^{+} \mathrm{CD} 38^{-} \mathrm{Lin}^{-}$cells in PB of SCD patients and normal (NL) donors (Figures 1 and 2). PB from NL donors contained 6.7 (range 1-11) CD $34^{+}$CD $38^{-}$Lin $^{-}$cells per $10^{5}$ PBMCs, and PB from
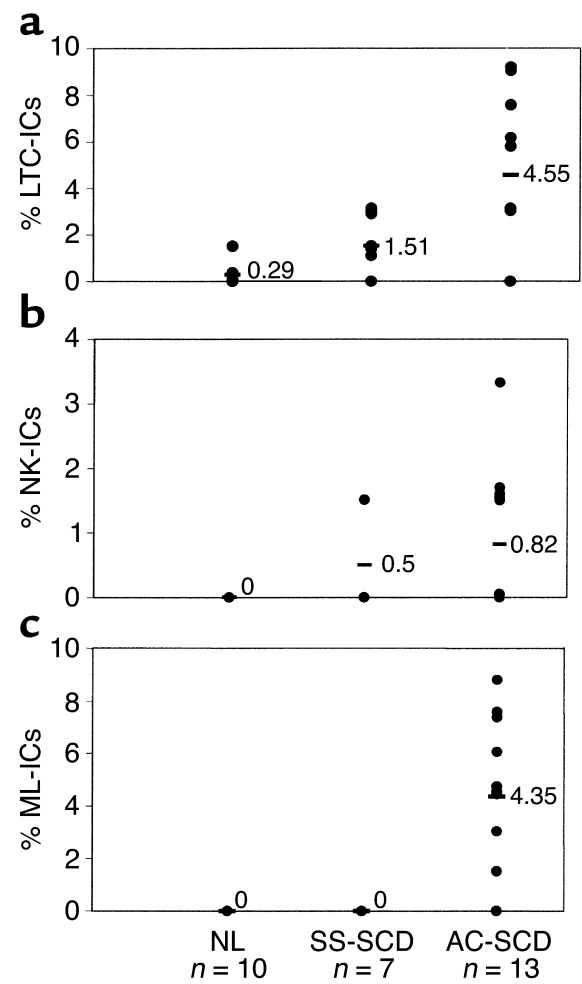
Table 2

Engraftment of CD34 ${ }^{+}$cells from PB of normal donors, SS-SCD patients, and AC-SCD patients

\begin{tabular}{|c|c|c|c|}
\hline \multirow[t]{2}{*}{ Cell type } & \multirow[t]{2}{*}{ CD $34^{+}$dose } & \multicolumn{2}{|c|}{$\begin{array}{c}\text { \% Human engraftme } \\
\text { in NOD/SCID } \\
\text { bone marrow }\end{array}$} \\
\hline & & FACS & $\begin{array}{c}\text { Quantitati } \\
\text { PCR }\end{array}$ \\
\hline Normal control $(n=5)$ & $2.0 \times 10^{4}$ to $5.0 \times 10^{4}$ & $0 \%$ & $0 \%$ \\
\hline $\operatorname{SS}-\operatorname{SCD}(n=5)$ & $2.1 \times 10^{4}$ to $3.6 \times 10^{4}$ & $0 \%$ & $0 \%$ \\
\hline \multicolumn{4}{|l|}{ AC-SCD } \\
\hline No. 1 & $2.0 \times 10^{5}$ & 1.9 & 1.75 \\
\hline No. 2 & $3.1 \times 10^{5}$ & 0.6 & 0.6 \\
\hline No. 3 & $2.6 \times 10^{5}$ & 1.4 & 1.5 \\
\hline No. 4 & $2.5 \times 10^{5}$ & 0.6 & 0.7 \\
\hline No. 5 & $3.7 \times 10^{5}$ & 0.6 & 0.6 \\
\hline No. 6 & $2.2 \times 10^{5}$ & 0.6 & 0.6 \\
\hline No. 7 & $3.3 \times 10^{5}$ & 2.1 & 1.9 \\
\hline No. 8 & $3.0 \times 10^{5}$ & 2.0 & 2.0 \\
\hline
\end{tabular}

$\mathrm{CD} 34^{+}$cells selected by immunomagnetic beads from $200 \mathrm{ml}$ PB of five NL donors, $50 \mathrm{ml} \mathrm{PB}$ of five SS-SCD patients, and $50 \mathrm{ml} \mathrm{PB}$ of eight AC-SCD patients were infused with irradiated carrier cells via the tail vein in NOD/SCID mice irradiated with $275 \mathrm{cGy}$. After 6 weeks, animals were sacrificed and marrow, blood, and spleen cells collected. The presence of human cells was determined by FACS (staining for human and mouse $\mathrm{CD}_{4} 5^{+}$cells) and by quantitative PCR as described in Methods.

patients with SCD in steady state contained 13.7 (range 1-23) $\mathrm{CD}^{3} 4^{+} \mathrm{CD} 38^{-} \mathrm{Lin}^{-}$cells per $10^{5} \mathrm{PBMCs}$. PB from patients with SCD in acute crisis (AC-SCD patients) had an average of 250 (range $38-880$ ) CD $34^{+} \mathrm{CD} 38$ Lin $^{-}$ cells per $10^{5}$ PBMCs, significantly more than in SS-SCD patients or normal controls $(P<0.01)$.

We next examined the proportion of $\mathrm{CD} 34^{+} \mathrm{CD}^{-} 8^{-\mathrm{Lin}^{-}}$ cells, from the three donor groups, that were ML-ICs, LTC-ICs, and NK-ICs. For these studies, CD34 ${ }^{+} \mathrm{CD} 38^{-} \mathrm{Lin}^{-}$cells were selected from $50-200 \mathrm{ml} \mathrm{PB}$. Because the number of $\mathrm{CD} 34^{+} \mathrm{CD} 38^{-} \mathrm{Lin}^{-}$cells was significantly lower in blood of NL donors and SS-SCD

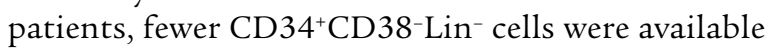
for evaluation from these individuals (11-66 from NL donors and 28-88 from SS-SCD patients) than from AC-SCD patients (66-132 cells). We could not detect ML-ICs among PB CD34 ${ }^{+} \mathrm{CD} 38^{-} \mathrm{Lin}^{-}$cells from NL donors or SS-SCD patients. CD34 ${ }^{+} \mathrm{CD} 38-\mathrm{Lin}^{-}$ cells in PB from normal donors included no cells that gave rise to NK-ICs, and $0.29 \%$ cells that gave rise to LTC-ICs only (range $0-0.5 \%$; only three of ten PB samples contained enough $\mathrm{CD} 34^{+} \mathrm{CD} 38$ Lin $^{-}$cells to evaluate LTC-IC frequency). CD $34^{+} \mathrm{CD} 38^{-} \mathrm{Lin}^{-}$cells

\section{Figure 4}

Multilineage engraftment of AC-SCD CD $34^{+}$cells in NOD/SCID mice. Bone marrow from mouse no. 3 was harvested as described and then stained with anti-human CD45 and anti-human lineage antibodies to demonstrate multilineage engraftment. Live cells were gated in R1, and then human CD45 was gated against the antibody of interest. Percentages of human lineage cells are shown on the FACS plots. from SS-SCD patients included $1.51 \%$ (range $0-3.03 \%)$ cells that gave rise to LTC-ICs only and $0.5 \%$ (range $0-1.51 \%$ ) cells that gave rise to NK-ICs only upon replating. In contrast, $\mathrm{CD} 34^{+} \mathrm{CD} 38^{-} \mathrm{Lin}^{-}$cells from AC-SCD patients included $4.55 \%$ (range $3.03-9.09 \%$ ) and $0.82 \%$ (range $0-3.03 \%$ ) cells that gave rise to either LTC-ICs only or NK-ICs only upon replating (Figure 3, a and b). However, because $4.35 \%$ of $\mathrm{CD} 34^{+} \mathrm{CD} 38^{-} \mathrm{Lin}^{-}$cells gave rise to at least one LTC-IC and one NK-IC, they were considered ML-ICs (Figure 3c). No CD34+CD38- $\mathrm{Lin}^{-}$cells from SS-SCD patients or from NL donors gave rise to LTC-ICs and NK-ICs; therefore, no ML-ICs could be detected $(P<0.05$ for LTC-IC frequencies, $P<0.01$ for NK-IC frequencies, and $P<0.001$ for ML-IC frequencies vs. $\mathrm{NL}$ or SS-SCD). A strong correlation was seen between the presence of LTC-ICs $\left(r^{2}=0.74\right)$ or NK-ICs $\left(r^{2}=0.96\right)$ and the presence of ML-ICs in the blood of AC-SCD patients.

We next tested whether PB CD $34^{+}$cells from SCD patients included SRCs. Fifty milliliters of blood was obtained from patients with SCD in acute crisis or steady state, and 200 milliliters was obtained from normal donors. CD $34^{+}$cells were selected, and all CD $34^{+}$cells were injected in sublethally irradiated NOD-SCID mice. Because of the differences in the number of $\mathrm{CD} 34^{+}$cells obtained from a given volume of $\mathrm{PB}$ among AC-SCD patients, SS-SCD patients, and $\mathrm{NL}$ donors, the total number of $\mathrm{CD} 34^{+}$cells injected varied significantly between the groups: $2.68 \times 10^{5} \pm$
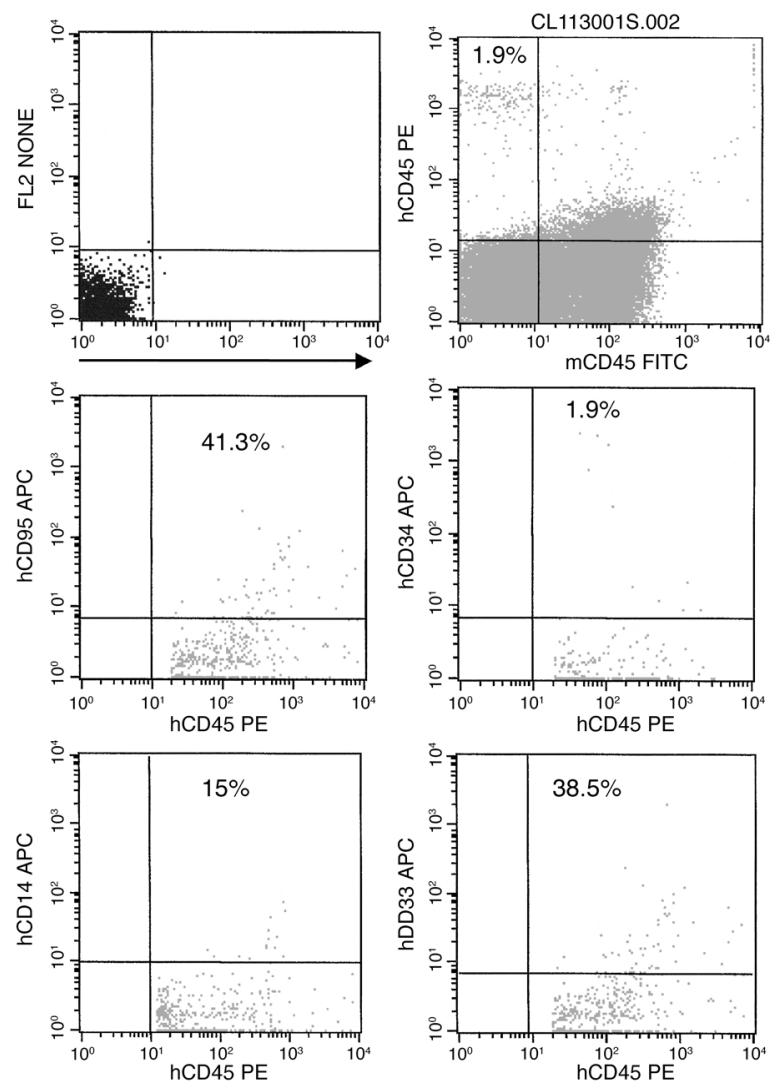


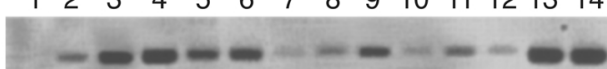

\section{Figure 5}

PCR confirmation of human hematopoietic cell engraftment in NOD/SCID mice transplanted with AC-SCD CD $34^{+}$cells. PCR for human DNA is shown. Lanes 1-3, spleens from mice nos. 1-3. Lanes 4-9, bone marrow from mice nos. 1-6. Lanes 10-12, PB from mice nos. 1-3. Lane 13, K562 cells. Lane 14, cord blood CD34+ cells. Normal mouse bone marrow was used as a control.

$0.62 \times 10^{5}$ for AC-SCD patients, $2.92 \times 10^{4} \pm 1.32 \times$ $10^{4}$ for SS-CSD patients, and $2.88 \times 10^{4} \pm 0.6 \times 10^{4}$ for normal donors $(P<0.01)$. Engraftment levels are shown in Table 2 . All animals that were injected with $\mathrm{CD} 34^{+}$cells from AC-SCD patients showed multilineage human cell engraftment by FACS, at levels ranging from $0.6 \%$ to $1.9 \%$ (Table 2; Figure 4). These results were confirmed by quantitative PCR for human DNA, which showed engraftment at levels ranging from $0.6 \%$ to $1.4 \%$ (Table 2 ; Figure 5 ). PCR for the $\beta$-globin gene also showed that engrafted cells contained the valine-to-glutamic-acid substitution at codon 6 (not shown). In contrast, animals that received $\mathrm{CD} 34^{+}$cells from SS-SCD patients did not show any human engraftment. Likewise, animals that received $\mathrm{CD} 34^{+}$cells from normal donors did not have human $\mathrm{CD}_{4} 5^{+}$cells. Control animals that received either irradiated normal cells alone or $\mathrm{CD} 34$ cells also did not show engraftment, as assessed by FACS or PCR (Table 2).

Bone marrow from mice with engraftment levels of about $2 \%$ human $\mathrm{CD}_{45} 5^{+}$cells $(n=2)$ was transplanted into secondary irradiated NOD/SCID recipients, and their marrow was again analyzed at 6 weeks for human engraftment. Both recipients showed $0.2 \%$ engraftment by FACS and PCR.

Increased levels of mobilizing cytokines are present in the $P B$ during acute crisis of SCD. Levels of SCF (Figure 6a), GCSF (Figure 6b), GM-CSF (Figure 6c), and IL-8 (Figure 6d) were measured in serum of NL donors and SCD patients. SCF was undetectable in the serum of normal donors. Levels of SCF in serum of SS-SCD patients were $11.67 \mathrm{pg} / \mathrm{ml}$ (range 1-22 $\mathrm{pg} / \mathrm{ml}$ ), whereas levels in serum of AC-SCD patients were $4,150 \mathrm{pg} / \mathrm{ml}$ (range $88-7,000 \mathrm{pg} / \mathrm{ml}$ ), representing a 200 -fold increase compared with SS-SCD patients $(P<0.01)$. Serum GCSF levels in normal controls averaged $859 \mathrm{pg} / \mathrm{ml}$ (range 594-966 pg/ml), similar to those for SS-SCD patients $(759 \mathrm{pg} / \mathrm{ml}$; range $654-871 \mathrm{pg} / \mathrm{ml}$ ). In contrast, serum levels of GCSF in AC-SCD patients were $2,000 \mathrm{pg} / \mathrm{ml}$ (range $1,820-2,180 \mathrm{pg} / \mathrm{ml})(P<0.05$ vs. SS-SCD group). GM-CSF was undetectable by ELISA in the serum of normal donors; SS-SCD patients had an average serum level of $1.5 \mathrm{pg} / \mathrm{ml}$ (range $0-12 \mathrm{pg} / \mathrm{ml}$ ), whereas levels in serum of AC-SCD patients averaged 1,049 $\mathrm{pg} / \mathrm{ml}$ (range $431-1,914 \mathrm{pg} / \mathrm{ml})(P<0.01$ for AC-SCD patients vs. SS-SCD patients and NL donors). Levels of IL-8 were also significantly higher in AC-SCD patients $(4,820 \mathrm{pg} / \mathrm{ml}$; range $466-7,015 \mathrm{pg} / \mathrm{ml})$ than in SS-SCD patients $(86 \mathrm{pg} / \mathrm{ml}$; range $41-465 \mathrm{pg} / \mathrm{ml})$ and $\mathrm{NL}$ donors $(58 \mathrm{pg} / \mathrm{ml}$; range $46-98 \mathrm{pg} / \mathrm{ml})$ $(P<0.01$ for AC-SCD vs. SS-SCD patients). ML-IC frequency in blood of AC-SCD patients correlated with SCF levels at $r^{2}=0.78$, GCSF levels at $r^{2}=0.50$, IL-8 levels at $r^{2}=0.72$, and GM-CSF levels at $r^{2}=0.58$.

Addition of SCF to GCSF results in increased mobilization of primitive progenitors in the PB of lymphoma patients. To further determine whether the presence of high levels of multiple cytokines in serum of AC-SCD patients might be responsible for the mobilization of ML-ICs in the blood, we evaluated the number of ML-ICs, LTC-ICs, and NK-ICs in the PB of patients with Hodgkin disease or non-Hodgkin lymphoma who were treated with either GCSF alone or GCSF plus SCF to mobilize PB progenitors for transplantation. Increased numbers of ML-ICs were present in lymphoma patients whose blood was mobilized with GCSF plus SCF (6.25\% ML-ICs [range 3.03-8.33\%] per $\mathrm{CD} 34^{+} \mathrm{CD} 38^{-} \mathrm{Lin}^{-}$cell) compared with patients whose blood was mobilized with GCSF alone $(1.7 \%$ ML-ICs [range 1.41-2.27\%] per $\mathrm{CD}^{+} 4^{+} \mathrm{CD} 38$ - $^{-}$in $^{-}$ cell). As we observed for AC-SCD and SS-SCD patients, the number of LTC-ICs among PB CD $34^{+}$CD $38-$ Lin $^{-}$cells was only marginally different (GCSF plus SCF, $18.22 \%$, range 15.9-31.82\%; GCSF alone, $13.45 \%$, range $7.58-18.94 \%$ ), whereas fewer NK-ICs were detected among $\mathrm{PB} \mathrm{CD}^{-} 4^{+} \mathrm{CD}^{-} 8^{-} \mathrm{Lin}^{-}$ cells from lymphoma patients treated with GCSF alone $(1.52 \%$, range $0-3.13 \%)$ compared with patients treated with GCSF plus SCF (8.91\%, range 4.55-15.17\%) (Figure 7, a-c).
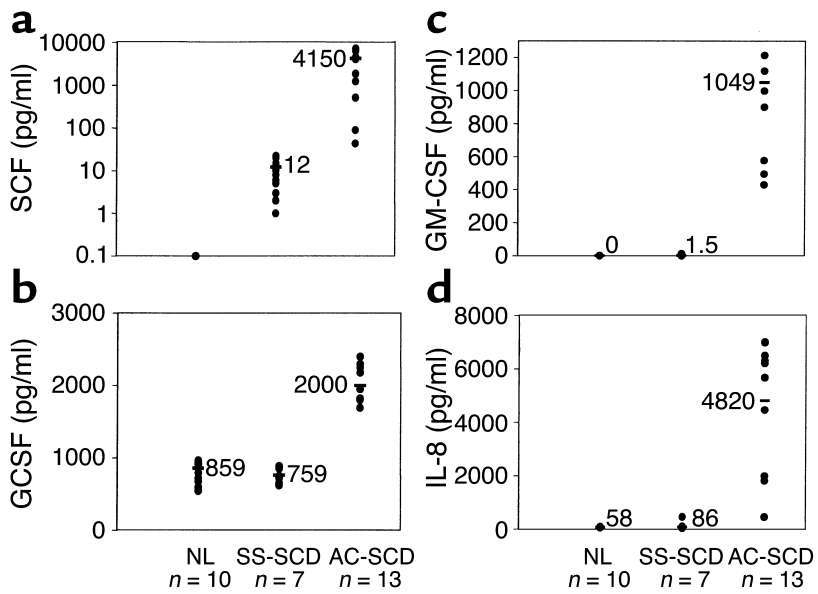

\section{Figure 6}

Elevated serum levels of SCF (a), GCSF (b), GM-CSF (c), and IL-8 (d) in serum of AC-SCD patients compared with NL donors and SS-SCD patients. Serum was collected from ten normal donors, seven SS-SCD patients, and 13 AC-SCD patients, and then frozen at $-80^{\circ} \mathrm{C}$. Levels of SCF, GCSF, GM-CSF, and IL- 8 were measured using ELISA. Differences between groups were analyzed by unpaired $t$ test. 

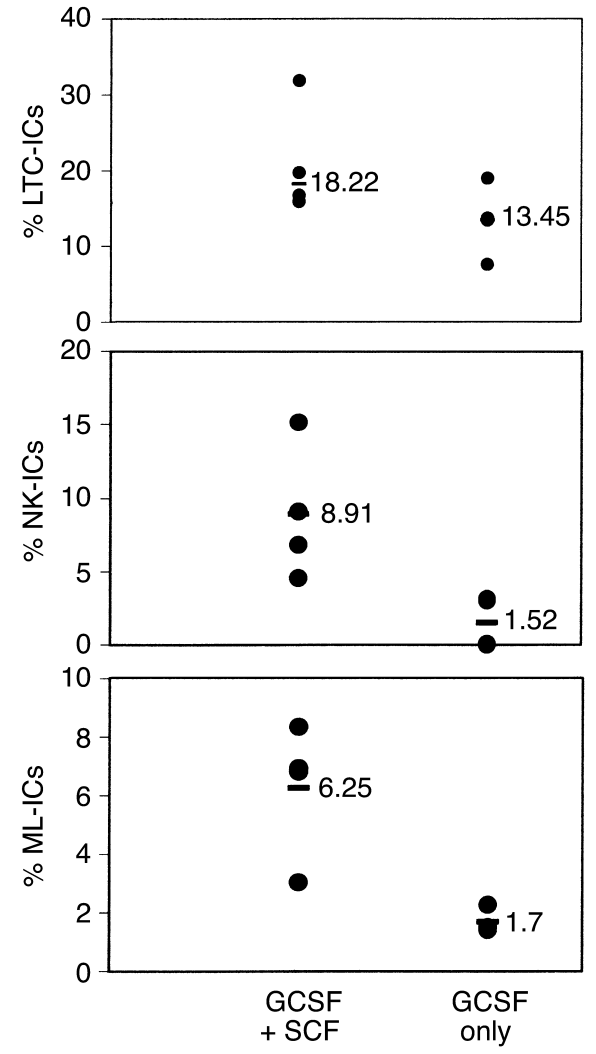

Figure 7

More LTC-ICs, NK-ICs, and ML-ICs are mobilized in PB following GCSF+SCF than following GCSF-only mobilization. Single CD $34^{+} \mathrm{CD} 38^{-}$Lin $^{-}$cells, selected by FACS from lymphoma patients who received GCSF+SCF mobilization (66-132 wells plated) and lymphoma patients who received GSCF-only mobilization (66-132 wells plated), were plated in the ML-IC assay as previously described (24). The frequency of LTC-ICs was enumerated by overlaying of cultures with clonogenic medium after 5 weeks. Cells were maintained for 2 weeks in expansion medium, and progeny were replated in two LTC-IC and two NK-IC cultures. The frequency of NK-ICs was enumerated by harvesting of plates after 5 weeks and evaluation of the cells for presence of CD56 ${ }^{+} \mathrm{NK}$ cells or CD19+ $\mathrm{B}$ cells by FACS as previously described (24). An ML-IC was identified when progeny of the initial CD34+CD38- Lin $^{-}$cell gave rise to at least one LTC-IC and at least one NK-IC. Significantly more NK-ICs and ML-ICs were present in $\mathrm{CD}^{+} 4^{+} \mathrm{CD} 38^{-}$Lin $^{-}$cells from blood mobilized with GCSF+SCF than in those from blood mobilized with GCSF only. Differences in LTC-IC frequency between the two groups were not significant. Differences between the groups were evaluated by $t$ test.

\section{Discussion}

SCD is the most common hematopoietic disease that results from a single gene defect. It would be treated successfully if efficient gene transfer into HSCs could be accomplished. Because transplantation of HSCs collected from mobilized blood brings about earlier hematopoietic recovery, it has replaced bone marrow HSC transplantation (28). However, toxicity caused by administration of cytokines to mobilize HSCs into the PB of patients with SCD has been observed (29). Several studies have shown that committed erythroid blast-forming unit progenitors as well as LTC-ICs are present in the blood of SCD patients (15). We show here, for the first time to our knowledge, that primitive progenitors, such as ML-ICs with both lymphoid and myeloid potential, as well as SRCs are spontaneously mobilized in AC-SCD patients. The presence of both ML-ICs and SRCs in the PB of AC-SCD patients is associated with significantly higher levels of SCF and GCSF in serum of these patients.

The LTC-IC assay measures primitive progenitors that, after 5 weeks, generate progenitors with myeloid but not lymphoid differentiation potential. However, a number of studies have shown that LTC-ICs do not correlate with engraftment of human hematopoietic progenitors (30-33). We have used the ML-IC assay to measure primitive progenitors in vitro. Although LTC-ICs and, to a lesser extent, NK-ICs could be detected in the PB of SS-SCD patients, ML-ICs were only found in the $\mathrm{PB}$ of AC-SCD patients. The ML-IC assay measures single progenitors that can give rise to secondary progenitors that reinitiate not only LTC-IC cultures, but also long-term lymphoid cultures in which NK cells and $B$ cells are produced (24). The multilineage differentiation of ML-ICs is thus one of the main characteristics of HSCs. Because the ML-IC assay measures progenitors in an in vitro system, it does not address another property of HSCs, namely the ability to reconstitute hematopoiesis in vivo. To demonstrate reconstitution of hematopoiesis, transplantation is required, such as in NOD/SCID murine recipients. In addition to ML-ICs, SRCs were also present in the blood of AC-SCD patients but not SS-SCD patients or NL donors. Our observations therefore confirm the notion that the presence of LTC-ICs in human samples at week 5 does not correlate with the presence of SRCs (34). However, we demonstrate here that the presence of ML-ICs, seen only in AC-SCD patents, correlates with the presence of SRCs, found only in PB of AC-SCD patients. Infusion of CD34+ cells from as little as $50 \mathrm{ml}$ AC-SCD blood gave rise to $0.6-1.9 \%$ human $\mathrm{CD} 45^{+}$cells after 6 weeks. Moreover, cells from two AC-SCD patients that engrafted in primary NOD/SCID recipients could be transferred to secondary recipients. Although we could not detect any ML-ICs or SRCs among CD $34^{+}$CD $38^{-}$Lin $^{-}$cells from $200 \mathrm{ml}$ blood of NL donors and $50 \mathrm{ml}$ blood of SS-SCD patients, there is evidence that nonmobilized PB of NL donors contains hematopoietic reconstituting cells $(35,36)$. Therefore, we believe that if larger volumes of blood were to be evaluated, ML-ICs and SRCs would be detectable in blood of SS-SCD patients and NL donors. Nevertheless, our studies indicate that a much higher number of ML-ICs and SRCs is detectable per ml of blood in AC-SCD patients than in SS-SCD patients and NL donors.

SCF levels are five- to 20 -fold higher in AC-SCD patients than in SS-SCD patients, and they correlate strongly with the presence of ML-ICs. SCF is an early-acting 
cytokine that activates the c-Kit receptor, a transmembrane tyrosine kinase receptor (37) expressed on some but not all HSCs $(38,39)$ and most hematopoietic progenitors. Administration of SCF to mice for 7 days results in depletion of candidate bone marrow stem cells and a corresponding reduction in radioprotective ability (40). A concomitant increase in both these hematopoietic parameters, as well as multilineage long-term reconstituting activity, is observed in spleen and PB (41). We also found that mobilization of ML-ICs in the blood of patients with lymphoma is enhanced when SCF is added to GCSF. Thus, increased levels of SCF in the blood of AC-SCD patients may be an important factor contributing to the spontaneous mobilization of primitive progenitors in the blood during sickle cell crisis.

Levels of IL-8 also correlated highly with the presence of ML-ICs. Fibbe et al. showed that mobilization of HSCs in mice and nonhuman primates by IL-8 (42) depends on the metalloproteinase gelatinase B. Whether these mechanisms also operate in human AC-SCD patients needs to be determined. Our data also confirm the findings of increased IL-8 and GM-CSF in SCD patients. We also found a correlation between GCSF levels and GM-CSF levels with the presence of ML-ICs, although the correlation was less strong than with SCF or IL-8. Expression of VCAM-1 is downregulated significantly when HSCs are mobilized using GCSF, apparently as a result of proteolysis by neutrophil-derived elastase and cathepsin G (43). Mechanisms underlying mobilization of HSCs by GM-CSF (44) have not yet been elucidated.

In some patients, acute crisis was associated with a bacterial or viral infection (Table 1). Thus, elevated levels of GCSF, GM-CSF, SCF, and IL-8 may be related, in this group of patients, to an anti-infectious response. However, in more than $50 \%$ of patients, no infection was diagnosed. The mechanism underlying the elevated levels of cytokines in this group of patients, therefore, cannot likely be attributed to an anti-infectious response but may be caused by tissue ischemia.

In conclusion, we demonstrate here, for the first time to our knowledge, that in AC-SCD patients primitive hematopoietic cells with ML-IC and SRC characteristics are spontaneously mobilized in the $\mathrm{PB}$. This mobilization is correlated significantly with high serum levels of HSCs, including SCF, IL-8, and, to a lesser extent, GM-CSF and GCSF during acute crisis. The presence of large numbers of $\mathrm{CD} 34^{+}$cells, $\mathrm{CD} 34^{+} \mathrm{CD} 38^{-} \mathrm{Lin}^{-}$cells, and functionally defined primitive progenitors such as ML-ICs and SRCs in the PB of AC-SCD patients even in the absence of mobilizing cytokines or chemotherapy indicates that HSCs could be collected by apheresis at the time of exchange transfusion during crisis (two collections would yield more than $2.1 \times 10^{6} \mathrm{CD} 34^{+}$cells per kg for a $70-\mathrm{kg}$ patient). This would remove the need for bone marrow harvests or potentially dangerous cytokine-induced mobilizations.

\section{Acknowledgments}

This work was supported by NIH grant PO1-HL55552 and the University Of Minnesota Academic Health Center.

1. Platt, O.S., Brambilla, D.J., and Rosse, W.F. 1994. Mortality in sickle cell disease. Life expectancy and risk factors for early death. N. Engl.J. Med. 330:1639-1644.

2. Johnson, F., Look, A., and Gockerman, J. 1984. Bone marrow transplantation in a patient with sickle cell anemia. N. Engl. J. Med. 311:780-783.

3. Van Besien, K., Bartholomew, A., and Stock, W. 2000. Fludarabinebased conditioning for allogeneic transplantation in adults with sickle cell disease. Bone Marrow Transplant. 26:445-459.

4. Walters, M., Storb, R., and Patience, M. 1999. Stable mixed chimerism after bone marrow transplantation for sickle cell disease. Blood. 94(Suppl. 1):645a. (Abstr.)

5. Pawliuk, R., et al. 2001. Correction of sickle cell disease in transgenic mouse models by gene therapy. Science. 294:2368-2371.

6. Bloutin, M.J., et al. 2000. Genetic correction of sickle cell disease: insights using transgenic mouse models. Nat. Med. 6:177-181.

7. Welte, K., Gabrilove, J., Bronchud, M.H., Platzer, E., and Morstyn, G. 1996. Filgastrim (r-metHuG-CSF): the first 10 years. Blood. 88:1907-1929.

8. Glaspy, J.A., Shpall, E.J., and LeMaistre, C.F. 1997. Peripheral blood progenitor cell mobilization using stem cell factor in combination with filgrastrim in breast cancer patients. Blood. 90:2939-2951.

9. Somlo, G., Sniecinski, I., der Veer, A., Longmate, J., and Knutson, G. 1999. Recombinant human thrombopoietin in combination with granulocyte colony-stimulating factor enhances mobilization of peripheral blood progenitor cells, increases peripheral blood platelet concentration, and accelerates hematopoietic recovery following high dose chemotherapy. Blood. 93:2798-2806.

10. Kronenwett, R., Martin, S., and Haas, R. 2000. The role of cytokines and adhesion molecules for mobilization of peripheral blood stem cells. Stem Cells. 18:320-329.

11. Begley, C.G., Basser, R., and Mansfield, R. 1997. Enhanced levels and enhanced clonogenic activity of blood progenitor cells following administration of stem cell factor plus granulocyte colony-stimulating factor to humans. Blood. 90:3378-3389.

12. Adler, B.K., et al. 2001. Fatal sickle cell crisis after granulocyte colonystimulating factor administration. Blood. 97:3313-3314.

13. Grigg, A.P. 2001. Granulocyte colony-stimulating factor induced sickle cell crisis and multi-organ dysfunction in a patient with compound heterozygous sickle cell/beta+ thalassemia. Blood. 97:3998-3999.

14. Perlingeiro, R.C.R., Costa, F.F., Saad, S.T.O., Arruda, V.R., and Queiroz, M.L.S. 1999. Spontaneous erythroid colony formation in Brazilian patients with sickle cell disease. Am. J. Hematol. 61:40-45.

15. Croizat, H., Ponchio, L., Nicolini, F.E., Nagel, R.L., and Eaves, C.J. 2000. Primitive haematopoietic progenitors in the blood of patients with sickle cell disease appear to be endogenously mobilized. $\mathrm{Br}$. J. Haematol. 111:491-497.

16. Croizat, H., Nagel, R., Ponchio, L., and Eaves, C. 1996. Characterization of primitive progenitors (LTC-IC) in the blood of patients with sickle cell disease. Blood. 88:497a. (Abstr.)

17. Laterveer, L., Lindley, I.J., Hamilton, M.S., Willemze, R., and Fibbe, W.E. 1995. Interleukin-8 induces rapid mobilization of hematopoietic stem cells with radio-protective activity and long-term myelolymphoid repopulating activity. Blood. 85:2269-2275.

18. Duits, A., Schnog, J., Lard, L., Saleh, A., and Rojer, A. 1998. Elevated IL-8 levels during sickle cell crises. Eur. J. Haematol. 61:302-305.

19. Croizat, H. 1994. Circulating cytokines in sickle cell patients during steady state. Br. J. Haematol. 87:592-597.

20. Lyman, S.D. 1998. Biologic effects and potential clinical applications of Flt3 ligand. Curr. Opin. Hematol. 5:192-197.

21. Abboud, M.R., et al. 2000. Elevated serum and bronchiolar lavage fluid levels of interleukin 8 and granulocyte colony stimulating factor associated with acute chest syndrome in patients with sickle cell disease. Br. J. Haematol. 111:482-490.

22. Croizat, H., and Nagel, R. 1998. Circulating BFU-E in sickle cell anemia: relationship to percent fetal hemoglobin and BPA-like activity. Exp. Hematol. 16:946-949.

23. Goodman, J.W., and Hodgson, G.S. 1962. Evidence for stem cells in the peripheral blood of mice. Blood. 19:702-714.

24. Punzel, M., et al. 1999. The myeloid-lymphoid initiating cell assay assesses the fate of multipotent human progenitors in vitro. Blood. 93:3750-3756.

25. Van der Loo, J.C.M., et al. 1998. Nonobese diabetic/severe combined immunodeficiency (NOD/SCID) mouse as a model to study the mobilization and engraftment of human peripheral blood stem cells. Blood. 92:2556-2570. 
26. Srour, E., et al. 1992. Sustained human hematopoiesis in sheep transplanted in utero in early gestation with fractionated human marrow cells. Blood. 79:1404-1410.

27. Larochelle, A., et al. 1995. Engraftment of immune deficient mice with primitive hematopoietic cells from $\beta$-thalassemia and sickle cell anemia patients: implications for evaluating human gene therapy protocols. Hum. Mol. Genet. 4:163-172.

28. Prowles, R., et al. 2000. Allogeneic blood and bone marrow stem-cel transplantation in haematological malignant diseases: a randomised trial. Lancet. 355:1231-1241.

29. Hoppe, C.C., and Walters, M.C. 2001. Bone marrow transplantation in sickle cell anemia. Curr. Opin. Oncol. 13:85-90.

30. Glimm, H., Oh, I.H., and Eaves, C.J. 2000. Human hematopoietic stem cells stimulated to proliferate in vitro lose engraftment potential during their $\mathrm{S} / \mathrm{G}(2) / \mathrm{M}$ transit and do not re-enter $\mathrm{G}(0)$. Blood. 96:4185-4193.

31. Gan, O.I., Murdoch, B., Larochelle, A., and Dick, J.E. 1997. Differential maintenance of primitive human SCID-repopulating cells, clonogenic progenitors, and long-term culture initiating cells after incubation on human bone marrow stromal cells. Blood. 90:641-650.

32. Uchida, N., Fujisaki, T., Eaves, A.C., and Eaves, C.J. 2001. Transplantable hematopoietic stem cells in human fetal liver have a $\mathrm{CD}^{2} 4^{+}$side population (SP) phenotype. J. Clin. Invest. 108:1071-1077. doi:10.1172/ JCI200113297.

33. Larochelle, A., et al. 1996. Identification of primitive human hematopoietic cells capable of repopulating NOD/SCID mouse bone marrow: implications for gene therapy. Nat. Med. 2:1329-1337.

34. Dorrell, C. Gan, O.I, Pereira, D.S., Hawley, R. G., and Dick, J.E. 2000. Expansion of human cord blood CD34(+)CD38(-) cells in ex vivo culture during retroviral transduction without a corresponding increase in
SCID repopulating cell (SRC) frequency: dissociation of SRC phenotype and function. Blood. 95:102-110.

35. Fleidner, T.M. 1998. The role of blood stem cells in hematopoietic cell renewal. Stem Cells. 16:13-29.

36. Stroncek, D.F., et al. 1997. Composition of peripheral blood progenitor cell components collected from healthy donors. Transfusion. 37:411-417.

37. Ashman, L.K. 1999. The biology of stem cell factor and its receptor C-kit. Int. J. Biochem. Cell Biol. 31:1037-1048.

38. Lyman, S.D., and Jacobsen, S.E. 1998. C-Kit ligand and Flt3 ligand: stem/progenitor cell factors with overlapping yet distinct activities. Blood. 91:1101-1108.

39. Uoshima, N., Ozawa, M., Kimura, S., and Tanaka, K. 1995. Changes in c-kit expression and effects of SCF during differentiation of human erythroid progenitor cells. Br. J. Haematol. 91:30-44.

40. Zsebo, K.M., et al. 1992. Radioprotection of mice by recombinant rat stem cell factor. Proc. Natl. Acad. Sci. U. S. A. 89:9464-9476.

41. Bodine, D.M., Siedel, N.E., Gale, M.S., Nienhuis, A.W., and Orlic, D. 1993. In vivo administration of stem cell factor to mice increases the absolute number of pluripotent hematopoietic stem cells. Blood. 82:445-455.

42. Fibbe, W.E., et al. 1999. Biology of IL-8-induced stem cell mobilization. Ann. N. Y. Acad. Sci. 872:71-82.

43. Levesque, J.P., Takamatsu, Y., Nilsson, S.K., Haylock, D.N., and Simmons, P.J. 2001. Vascular cell adhesion molecule-1 (CD106) is cleaved by neutrophil proteases in the bone marrow following hematopoietic progenitor cell mobilization by granulocyte colony-stimulating factor. Blood. 98:1289-1297.

44. Fischmeister, G., and Gadner, H. 2000. Granulocyte colony-stimulating factor versus granulocyte-macrophage colony-stimulating factor for collection of peripheral blood progenitor cells from healthy donors. Curr. Opin. Hematol. 7:150-155. 